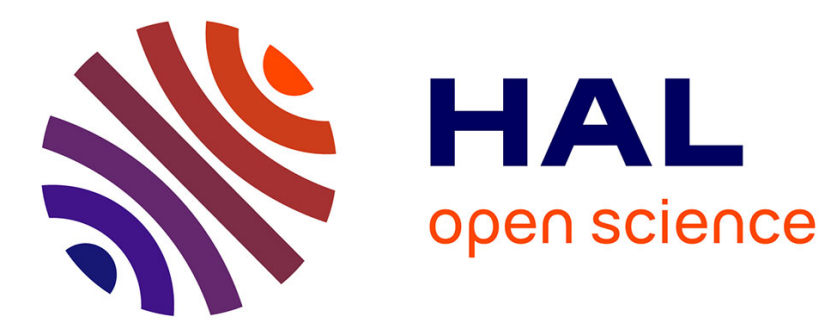

\title{
Properties study of silicon carbide thin films prepared by electron cyclotron resonance plasma technology
}

\author{
A. Valovič, J. Huran, M. Kučera, A.P. Kobzev, Š. Gaži
}

\section{To cite this version:}

A. Valovič, J. Huran, M. Kučera, A.P. Kobzev, Š. Gaži. Properties study of silicon carbide thin films prepared by electron cyclotron resonance plasma technology. European Physical Journal: Applied Physics, 2011, 56 (2), pp.24013. 10.1051/epjap/2011110153 . hal-00746211

\section{HAL Id: hal-00746211 \\ https://hal.science/hal-00746211}

Submitted on 28 Oct 2012

HAL is a multi-disciplinary open access archive for the deposit and dissemination of scientific research documents, whether they are published or not. The documents may come from teaching and research institutions in France or abroad, or from public or private research centers.
L'archive ouverte pluridisciplinaire $\mathbf{H A L}$, est destinée au dépôt et à la diffusion de documents scientifiques de niveau recherche, publiés ou non, émanant des établissements d'enseignement et de recherche français ou étrangers, des laboratoires publics ou privés. 


\title{
Properties study of silicon carbide thin films prepared by electron cyclotron resonance plasma technology
}

\author{
A. Valovič ${ }^{1 a}, J \operatorname{Huran}^{1}$, M. Kučera ${ }^{1}$, A.P. Kobzev ${ }^{2}$, and Š. Gaži ${ }^{1}$ \\ ${ }^{1}$ Institute of Electrical Engineering, Slovak Academy of Sciences, Dúbravská cesta 9, \\ 84104 Bratislava, Slovakia \\ ${ }^{2}$ Joint Institute for Nuclear Research, 141980 Dubna, Russian Federation
}

\begin{abstract}
Silicon carbide films were deposited at two deposition temperature 350 ${ }^{\circ} \mathrm{C}$ and $450{ }^{\circ} \mathrm{C}$ by means of ECR plasma reactor with two gas mixtures: 1 . gas mixture, $\mathrm{SiH}_{4}(5 \mathrm{sccm}), \mathrm{CH}_{4}(14 \mathrm{sccm}), \operatorname{Ar}(6 \mathrm{sccm}), \mathrm{NH}_{3}(2 \mathrm{sccm})$ and 2. gas mixture $\mathrm{SiH}_{4}(5 \mathrm{sccm}), \mathrm{CH}_{4}(14 \mathrm{sccm}), \mathrm{H}_{2}(6 \mathrm{sccm}), \mathrm{NH}_{3}(2 \mathrm{sccm})$. The concentration of species in the $\mathrm{SiC}$ films was determined by Rutherford backscattering spectrometry (RBS) and elastic recoil detection (ERD) analytical method simultaneously. Chemical compositions were analyzed by infrared (IR) spectroscopy. Photoluminescence (PL) spectra were measured at $300 \mathrm{~K}$. The RBS and ERD results showed that the concentrations of $\mathrm{Si}$ and $\mathrm{C}$ in the films are practically the same. The concentration of hydrogen decreased from 30 to 22 at.\% with an increasing sample deposition temperature. The films contain a small amount of nitrogen and oxygen. IR results showed the presence of Si-C, Si-N, Si$\mathrm{H}, \mathrm{C}-\mathrm{H}$ and Si-O bonds. PL results showed the decrease of the PL intensity with an increasing sample deposition temperature.
\end{abstract}

\section{Introduction}

Thin-film manufacturing methods using gas mixture consisting of two or more gases such as $\mathrm{SiH}_{4}-\mathrm{CH}_{4}$ is used for the production of thin-film transistors and other electronic devices and industrial products [1]. Silicon carbide has attracted much interest for wide range of applications. With its wide band gap, excellent thermal properties and large bonding energy, silicon carbide films are ideal for optoelectronic blue and ultra-violet wavelength emissions operating at high a e-mail: albin.valovic@savba.sk 
power levels, high temperatures and caustic environments [2]. The significance of this material follows from the fact that its electrical and optical properties can be controlled by varying the carbon, silicon and hydrogen composition of the film. PECVD technique offers an attractive opportunity to fabricate amorphous hydrogenated $\mathrm{N}$-doped $\mathrm{SiC}$ films at intermediate substrate temperatures and it provides high quality films with good adhesion, good coverage of complicated substrate shapes and high deposition rate [3]. Recently, Si-rich a-SiC $\mathrm{x}: \mathrm{H}$ films have attracted new attention in the photovoltaic community, since this material has shown excellent electronic surface passivation of c-Si comparable with thermal $\mathrm{SiO}_{2}$ and low temperature amorphous silicon nitride $\left(\mathrm{a}-\mathrm{SiN}_{\mathrm{x}}\right)$ passivation [4]. Silicon carbide films were deposited on silicon substrate with ECR-CVD reactor and photoluminescence was measured at temperatures between 100 and $300 \mathrm{~K}$ [5]. It consists of a relatively broad band centered at $450 \mathrm{~nm}$ and a second narrow band at $400 \mathrm{~nm}$ in the near stoichiometric samples. The crystallization of SiC correlates with the occurrence of a strong PL band which is strongly reduced after hydrogen passivation [6]. Among all the diagnostic methods of generated plasma, the advantage of the OES technique is to give local information on emitting chemical species with no disturbance of the investigated region [7].

In this contribution the attention has been focused to the structural and photoluminescence properties of silicon carbide films prepared by the electron cyclotron resonance plasma enhanced chemical vapor deposition (PECVD). The structural properties were investigated by RBS, ERD and Fourier transform infrared (FTIR) spectroscopy. PL measurement was used for photoluminescence properties investigations. Spectroscopic ellipsometry was used for optical characterization of the films.

\section{Experiment}

Silicon carbide films were deposited at two deposition temperatures, $350{ }^{\circ} \mathrm{C}$ and $450{ }^{\circ} \mathrm{C}$ by means of ECR plasma experimental facility with two gas mixtures: 1. gas mixture, $\mathrm{SiH}_{4}(5 \mathrm{sccm})$, $\mathrm{CH}_{4}(14 \mathrm{sccm}), \operatorname{Ar}(6 \mathrm{sccm}), \mathrm{NH}_{3}(2 \mathrm{sccm})$, samples F1(substrate temperature $\left.350{ }^{\circ} \mathrm{C}\right), \mathrm{F} 2\left(450{ }^{\circ} \mathrm{C}\right)$ and 2. gas mixture $\mathrm{SiH}_{4}(5 \mathrm{sccm}), \mathrm{CH}_{4}(14 \mathrm{sccm}), \mathrm{H}_{2}(6 \mathrm{sccm}), \mathrm{NH}_{3}(2 \mathrm{sccm})$, samples $\mathrm{F} 3\left(350{ }^{\circ} \mathrm{C}\right)$, $\mathrm{F} 4\left(450{ }^{\circ} \mathrm{C}\right)$. Schematic diagram of the ECR experimental facility used in this research is shown in Fig.1. The microwave power $(2.45 \mathrm{GHz}, 400 \mathrm{~W})$ was guided through a rectangular waveguide and introduced into the ECR magnetron excitation chamber (with dimensions high: $20 \mathrm{~cm}$, 
diameter: $25 \mathrm{~cm}$ ) through a quartz window. The magnetron controlled a magnetic field profile that serves to extract the ECR plasma into the deposition chamber (with dimensions high: $20 \mathrm{~cm}$, diameter: $35 \mathrm{~cm}$ ). All the reactant gases, with the exception of argon and hydrogen, were introduced into the deposition chamber. Argon and hydrogen are introduced directly into the excitation chamber. Data from sensor are used at manipulating with tuners. Sample holder in deposition chamber is with diameter $15 \mathrm{~cm}$. A p-type silicon wafer with resistivity $2-7 \Omega \mathrm{cm}$ and (100) orientation were used as the substrate for the $\mathrm{SiC}$ films. Concentration of species in the films were analyzed using RBS and ERD analytical method simultaneously [8]. Chemical compositions were analyzed by infrared spectroscopy using FT-IR Nicolet 3700 spectrometer in absorption mode and the absorption spectra of prepared substrate were subtracted from the film spectra. The IR spectra were measured from 4000 to $400 \mathrm{~cm}^{-1}$. The thickness and refractive index were determined by spectroscopic ellipsometry. For this purpose a SpecEl-2000 spectroscopic ellipsometer (400 - $900 \mathrm{~nm})$ manufactured by Micropac, software Scout from Wolfgang Theiss and an O'Leary-Johnson-Lim (OJL) model [9] was used. Photoluminescence spectra were recorded at room temperature. The samples were pumped by $20 \mathrm{~mW}$ power of a $488 \mathrm{~nm}$ line of an argon ion laser. The luminescence radiation was filtered by a quarter-meter monochromator and detected by a photomultiplier tube. The detector signal was amplified by a standard lock-in technique.

\section{Results and discussion}

Spectroscopic ellipsometry analysis indicated that the refractive index were in the range of 2.2 to 2.3 for all samples and change a little with change deposition temperature and gas mixtures. An example of plasma optical emission spectrum generated by a $\mathrm{SiH}_{4}$ and $\mathrm{CH}_{4}$ glow discharge is shown in Fig.2. When fabricating a-SiC:H film from $\mathrm{SiH}_{4}$ and $\mathrm{CH}_{4}$, it is known that the $\mathrm{I}\left(\mathrm{CH}^{*}\right)$ and $\mathrm{I}\left(\mathrm{SiH}^{*}\right)$ ratio, $\mathrm{I}\left(\mathrm{CH}^{*}\right) / \mathrm{I}\left(\mathrm{SiH}^{*}\right)$, is in a proportional relationship to the ratio of the numbers of carbon and silicon atoms inside the film. RBS(Fig.3.) and $\operatorname{ERD(Fig.4.)~analysis~indicated~that~the~}$ films contain silicon, carbon, nitrogen, hydrogen and small amount of oxygen. The concentrations of species for two series of samples are presented in Table. 1. From the concentration results we can conclude that the concentration of hydrogen decrease with increase deposition temperature and change a little with changing carrier gas argon to hydrogen. Films 
Table 1 Concentration of species in SiC films determined by RBS and ERD

\begin{tabular}{lccccc}
\hline $\begin{array}{l}\text { Sample } \\
\text { no. }\end{array}$ & $\begin{array}{c}\text { Silicon } \\
\text { (at.\%) }\end{array}$ & $\begin{array}{c}\text { Carbon } \\
\text { (at.\%) }\end{array}$ & $\begin{array}{c}\text { Hydrogen } \\
\text { (at.\%) }\end{array}$ & $\begin{array}{c}\text { Nitrogen } \\
\text { (at.\%) }\end{array}$ & $\begin{array}{c}\text { Oxygen } \\
\text { (at.\%) }\end{array}$ \\
\hline F1 & 28 & 34 & 27 & 9 & 2 \\
F2 & 30 & 35 & 22 & 10 & 3 \\
F3 & 27 & 34 & 30 & 7 & 2 \\
F4 & 29 & 35 & 26 & 7 & 3 \\
\hline
\end{tabular}

prepared with second gas mixture contain more hydrogen and smaller amount of nitrogen. It can be explained by more hydrogen in plasma and eliminating of nitrogen incorporation into films. Figure 5 shows IR absorption spectra of silicon carbide films F2 and F4. There are very small differences between IR spectra. The band at 2800 to $3000 \mathrm{~cm}^{1}$ is attributed to stretching vibration of the $\mathrm{CH}_{\mathrm{n}}$ group in both the $\mathrm{sp}^{2}\left(2880 \mathrm{~cm}^{-1}\right)$ and $\mathrm{sp}^{3}\left(2920 \mathrm{~cm}^{-1}\right)$ configurations. The band at $2100 \mathrm{~cm}^{-1}$ is due to $\mathrm{SiH}_{\mathrm{m}}$ stretching vibrations [10]. The band at $780 \mathrm{~cm}^{-1}$ can be assigned to $\mathrm{Si}-\mathrm{C}$ stretching vibration. Two additional peaks centered at 1250 and $1350 \mathrm{~cm}^{-1}$, can also be attributed to $\mathrm{C}-\mathrm{H}$ bonds; the absorption bands from 1200 to $1500 \mathrm{~cm}^{-1}$ are due to bending and scissioring modes of $\mathrm{CH}_{2}, \mathrm{CH}_{3}, \mathrm{Si}\left(\mathrm{CH}_{3}\right)$, and $\mathrm{C}\left(\mathrm{CH}_{3}\right)$. Modes in the region 1500 and $1600 \mathrm{~cm}^{-1}$ are attributed C-C stretching vibrations [11]. The signals occur between 930 and $1200 \mathrm{~cm}^{-1}$ which are superposition of several $\mathrm{C}-\mathrm{H}, \mathrm{Si}-\mathrm{O}$ and $\mathrm{Si}-\mathrm{N}$ vibrations $[12,13]$. Figure 6 shows PL spectra of the 1 st series of the samples. In the figure, one can see a decrease of the PL intensity with a sample deposition temperature. At the same time, a broadening of the spectra and increase of a relative portion of the low-energy tail could be assessed. Such luminescent properties are generally the attributes of a worsened quality of a material, i. e. enhanced concentration of crystalline imperfections and non-radiative centers. A similar decrease of the PL intensity with a substrate temperature was observed by other authors $[14,15]$. They conclude the strong PL intensity decrease for substrate temperatures above $300 \mathrm{~K}$ was caused by creation of unoccupied dangling bonds which act as the non-radiative centers. Figure 7 depicts PL spectra of the 2nd series of the samples. The PL intensity is almost equal for both samples but sample prepared at higher growth temperature shows broader spectrum and a larger low-energy tail. It implies a higher concentration of defects and non-radiative centers. Role of hydrogen can be explained as passivation of defects and then higher concentration of hydrogen in films result in higher PL 
intensity. It can be shown in the case of samples F2 and F4 but the problem is more complex. In all PL spectra, the low-energy tail is rapidly cut because of a large decrease of the photomultiplier intensity at approx. $820 \mathrm{~nm}$.

\section{Conclusion}

We have investigated the structural and photoluminescence properties of $\mathrm{SiC}$ films prepared by electron cyclotron resonance plasma enhanced chemical vapor deposition at temperatures $350{ }^{\circ} \mathrm{C}$ and $450{ }^{\circ} \mathrm{C}$. The RBS results showed that the concentrations of $\mathrm{Si}$ and $\mathrm{C}$ in the films are practically the same. The concentration of hydrogen decreased from 30 to 22 at.\% with an increasing sample deposition temperature. The films contain a small amount of nitrogen and oxygen. IR results showed the presence of $\mathrm{Si}-\mathrm{C}, \mathrm{Si}-\mathrm{N}, \mathrm{Si}-\mathrm{H}, \mathrm{C}-\mathrm{H}$ and $\mathrm{Si}-\mathrm{O}$ bonds. PL results showed the decrease of the PL intensity with an increasing sample deposition temperature. At the same time, from the spectra one can assess a gradual broadening of the spectra and an increase of a relative portion of the low-energy tail. With increasing the growth temperature, the hydrogen amount in the samples falls down. It is known that hydrogen passivates dangling bonds in such a type of a material. Indeed, one can see coincidence of this observation with a degradation of PL spectra.

\section{Acknowledgement}

This research has been supported by the: CENTE II(0.6), ITMS code 26240120019, supported by the Research \& Development Operational Program funded by the ERDF ijjand Slovak Research and Development Agency under the contracts APVV-0713-07 and SK-UA-0011-09.

\section{References}

1. M. Motohashi, K. Ashibu, Y. Hiruta, and K. Homma, Electronics and Communications in Japan, 90, 9 (2007)

2. V.M. Ng, M. Xu, S.Y. Huang, J.D. Long, and S. Xu, Thin Solid Films, 506-507, 283 (2006)

3. H. Colder, P. Marie, L. Pichon, and R. Rizk, Phys. Stat. Sol. (c), 1, 269 (2004) 
4. M. Vetter, C. Voz, R. Ferre, I. Martin, A. Orpella, J. Puigdollers, J. Andreu, and R. Alcubila, Thin Solid Films, 511-512, 290 (2006)

5. R. Reitano, G. Foti, C.F. Pirri, F. Giorgis, and P. Mandracci, Mat. Sci. Engn. C 15, 299 (2001)

6. M. Künle, T. Kaltenbach, P. Löper, A. Hartel, S. Janz, O. Eibl and K-G. Nickel, Thin Solid Films, 519, 151 (2010)

7. L. Thomas, E. Tomasella, J. M. Badie, R. Berjoan and M. Ducarroir, Chem. Vap. Deposition 9, $130(2003)$

8. A.P. Kobzev, J. Huran, D. Maczka and M. Turek, Vacuum 83, S124 (2009)

9. S.K. O’Leary, S.R. Johnson and P.K. Lim, J. Appl. Phys. 82, 3334 (1997)

10. S.F. Yoon and J.Ahn, J. Mater. Sci Technol. 13, 189 (1997)

11. T. Friessnegg, M. Boudreau, P. Mascher, A. Knights, P.J. Simpson and W. Puff, J. Appl. Phys. 84, 786 (1998)

12. M.N. Fraga, M. Massi, I.C. Oliviera, H.S. Maciel, S.G.S. Filho, R.D. Mansano, J. Mater. Sci.

19, $835(2008)$

13. M. Künle, T. Kaltenbach, P. L $\square$ per, A. Hartel, S.Janz, O. Eibl and K-G. Nickel, Thin Solid Films 519, 151(2010)

14. H. Munekata, S. Murasato and H. Kukimoto, Appl. Phys. Lett., 37, 536 (1980)

15. J. Niemann, W. Bauhoffer, Thin Solid Films 352, 249 (1999) 


\section{Figure captions}

Fig. 1. Schematic diagram of the ECR experimental facility and optical emission spectroscopy.

Fig. 2. Optical emission spectrum of $\mathrm{SiH}_{4}, \mathrm{CH}_{4}$ and $\mathrm{NH}_{3}$ glow discharge at $1.5 \mathrm{~Pa}$ with small amount of Ar for actinometry method in the case of 2 nd type of gas mixture.

Fig. 3. RBS spectra of samples F2 and F4 which represent spectra from all samples of both series

Fig. 4. ERD spectra of samples F2 and F4 which represent spectra from all samples of both series

Fig. 5. FTIR spectra obtained from as-deposited silicon carbide single layers F2 and F4.

Fig. 6. PL spectra of samples F1 and F2 measured at room temperature. Samples were prepared at different temperature in 1 . gas mixture glow discharge.

Fig. 7. PL spectra of samples F3 and F4 measured at room temperature. Samples were prepared at different temperature in 2 . gas mixture glow discharge. 

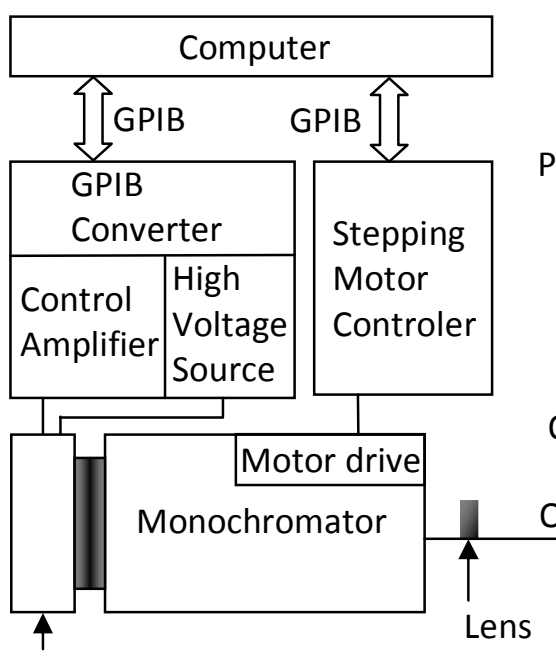

Photomultiplier

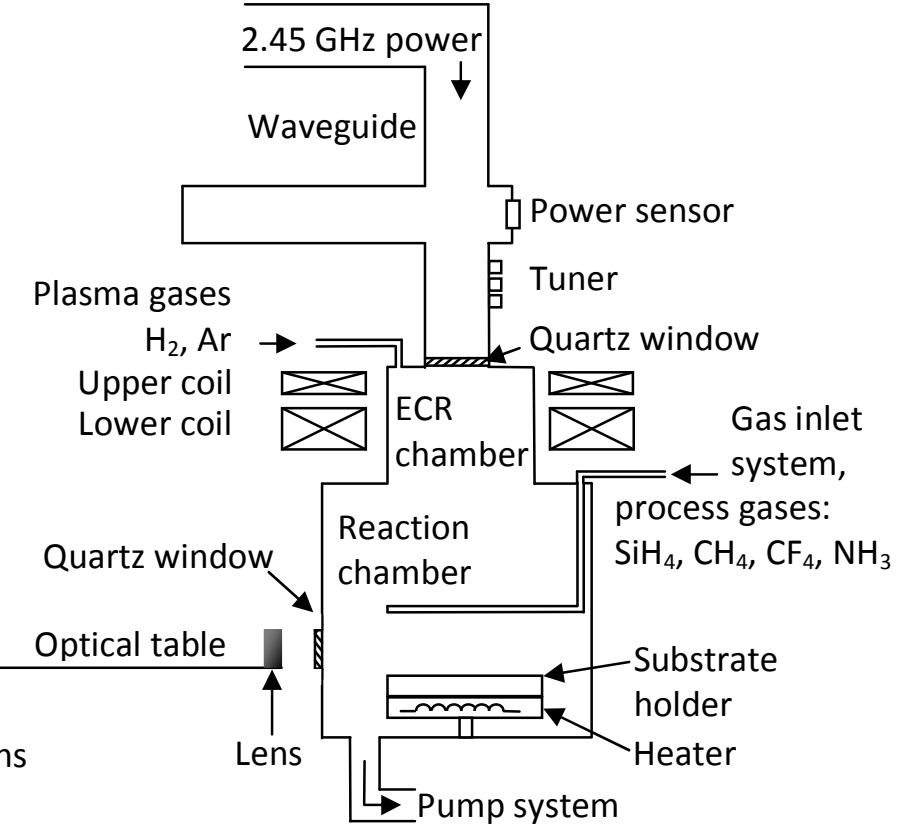

Fig. 1 


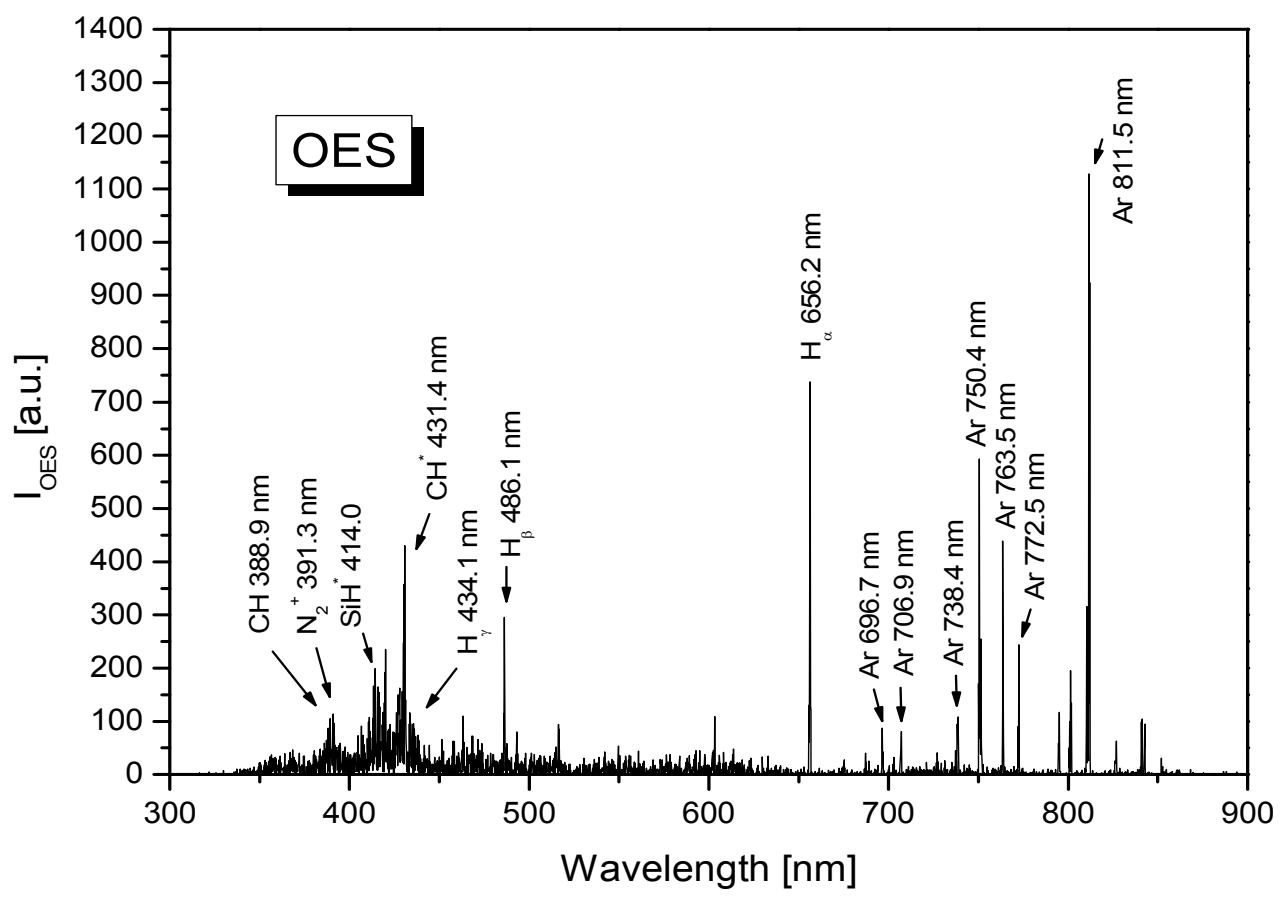

Fig. 2 


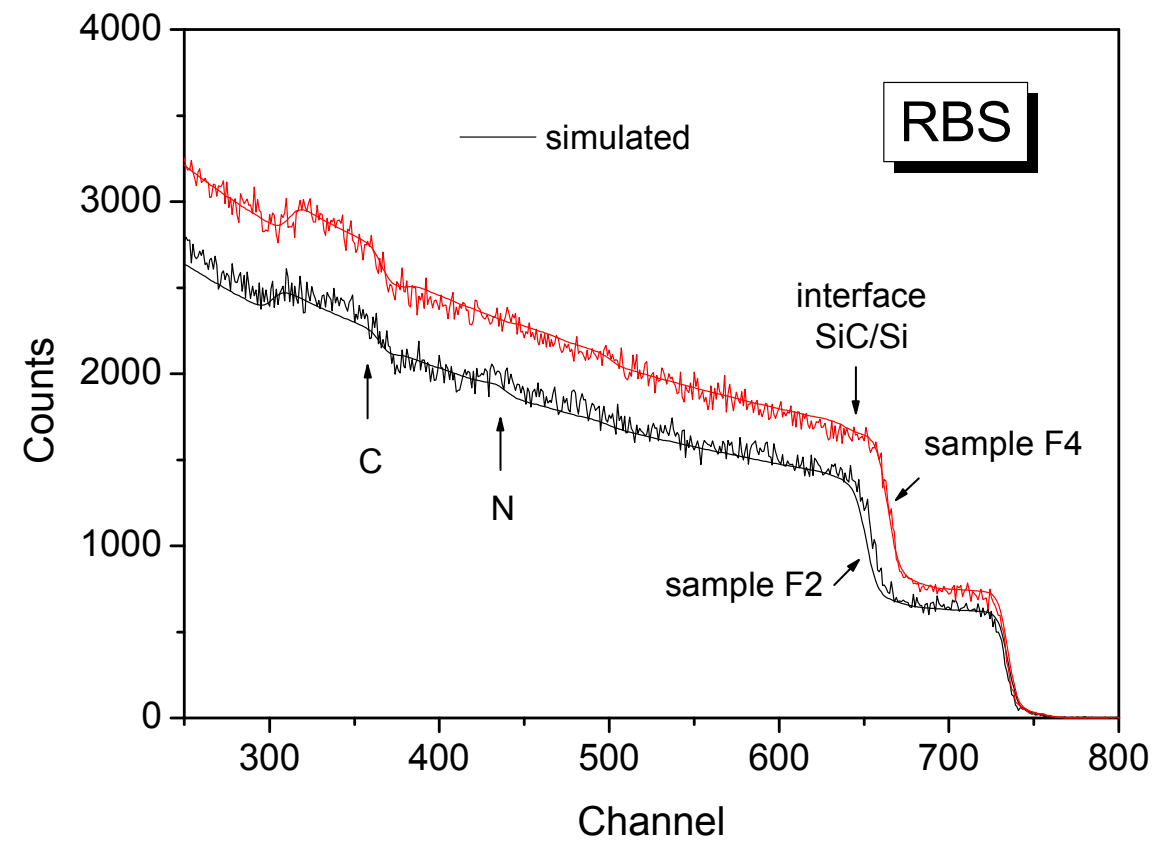

Fig. 3 


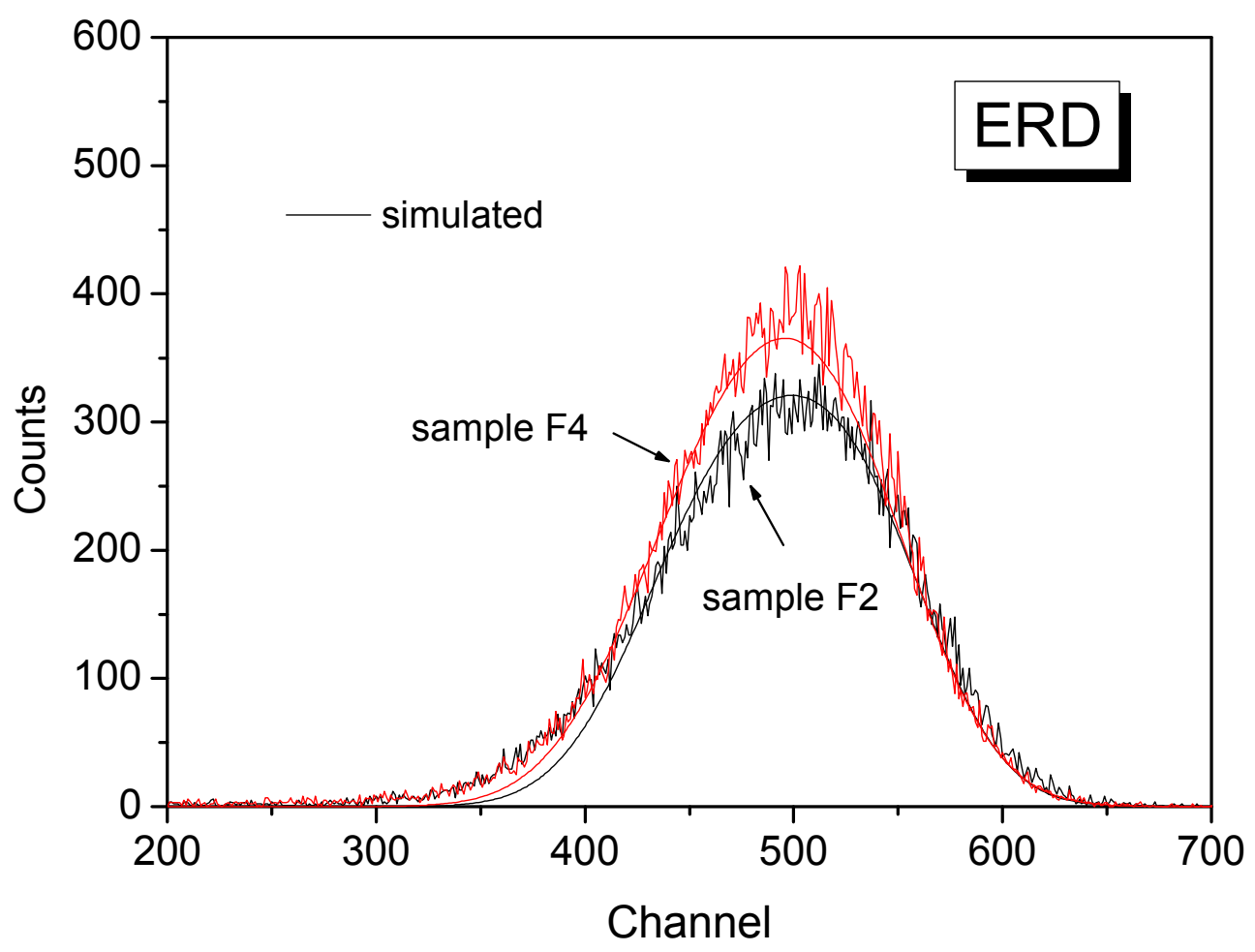

Fig. 4 


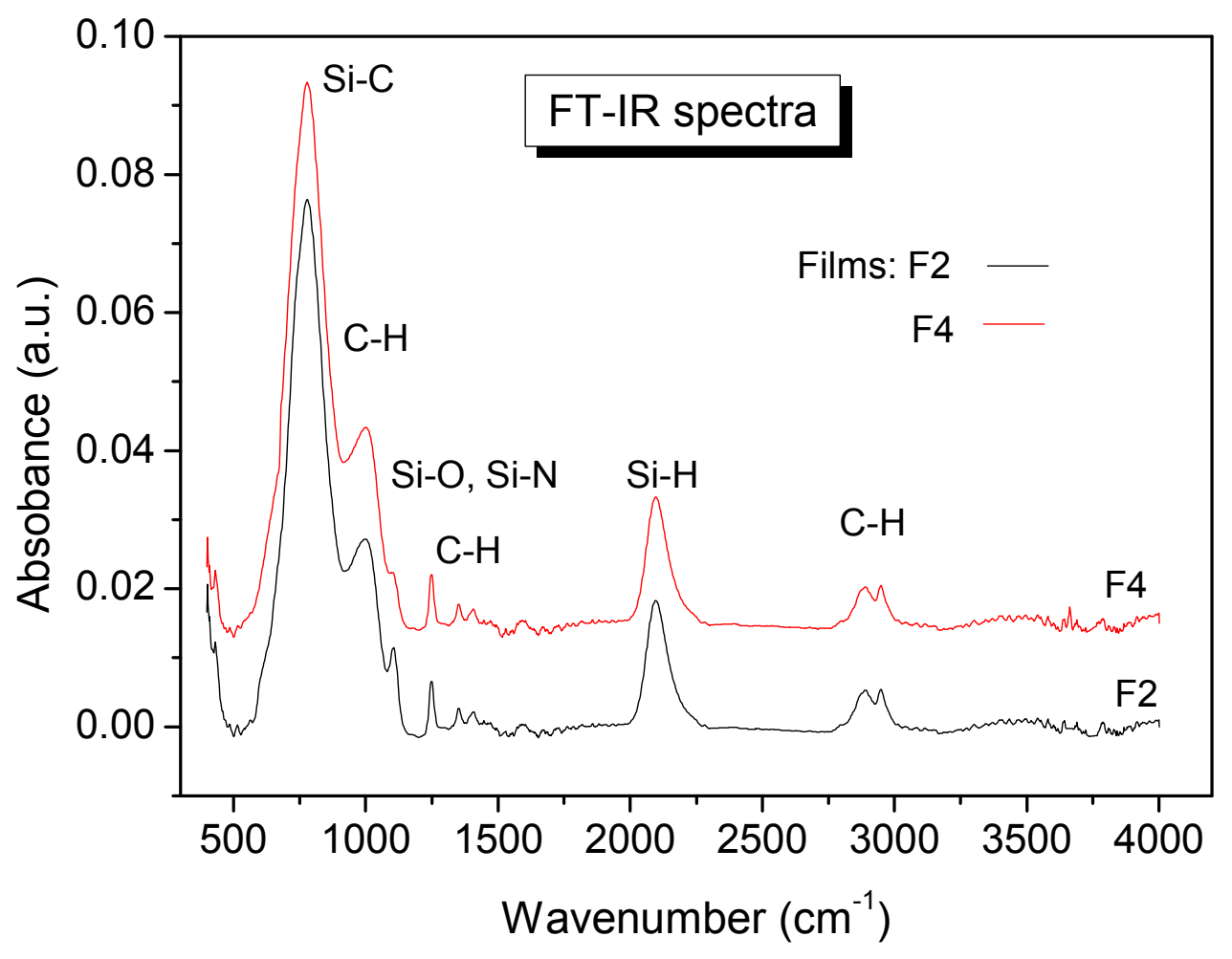

Fig. 5 


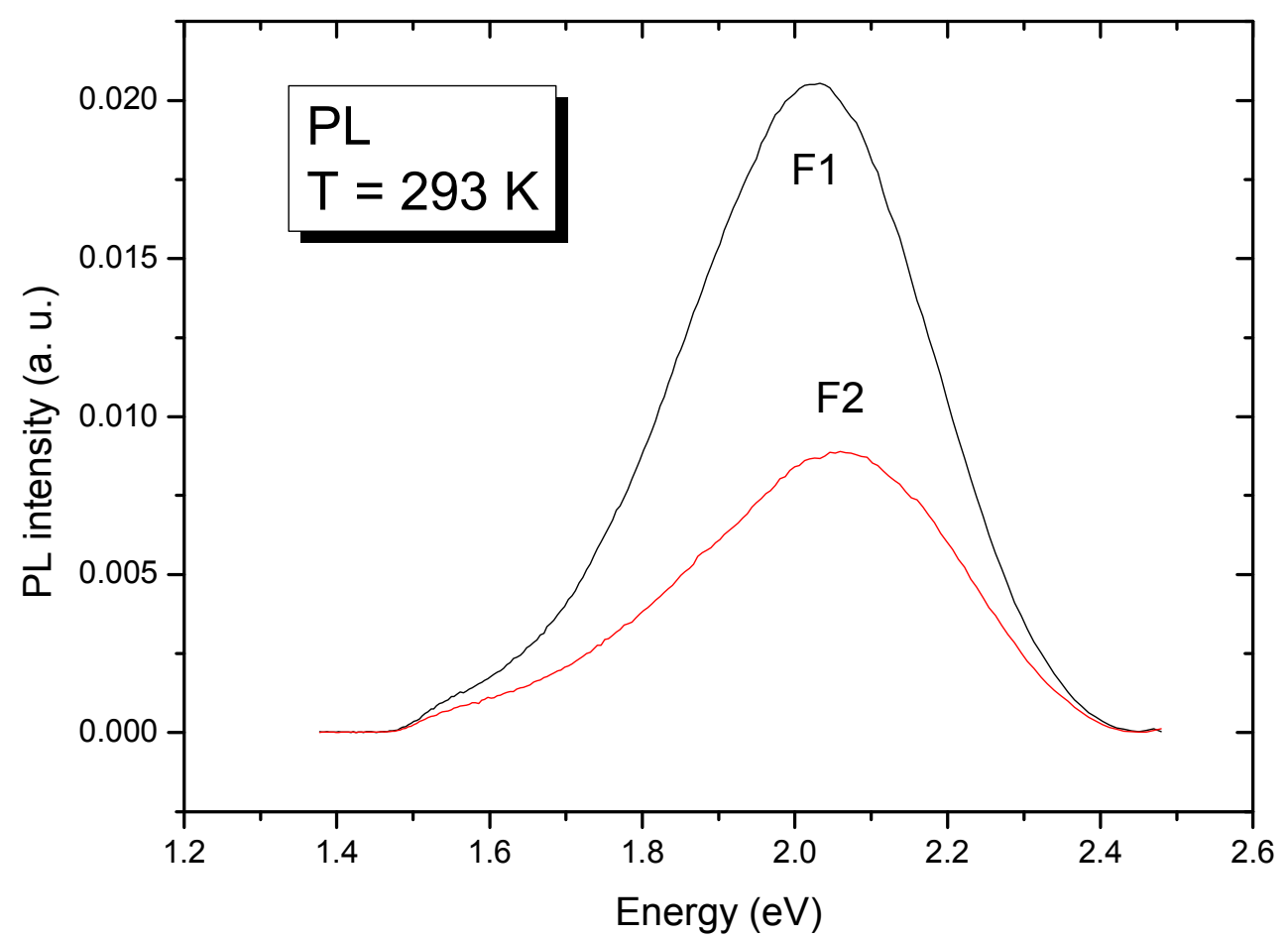

Fig. 6 


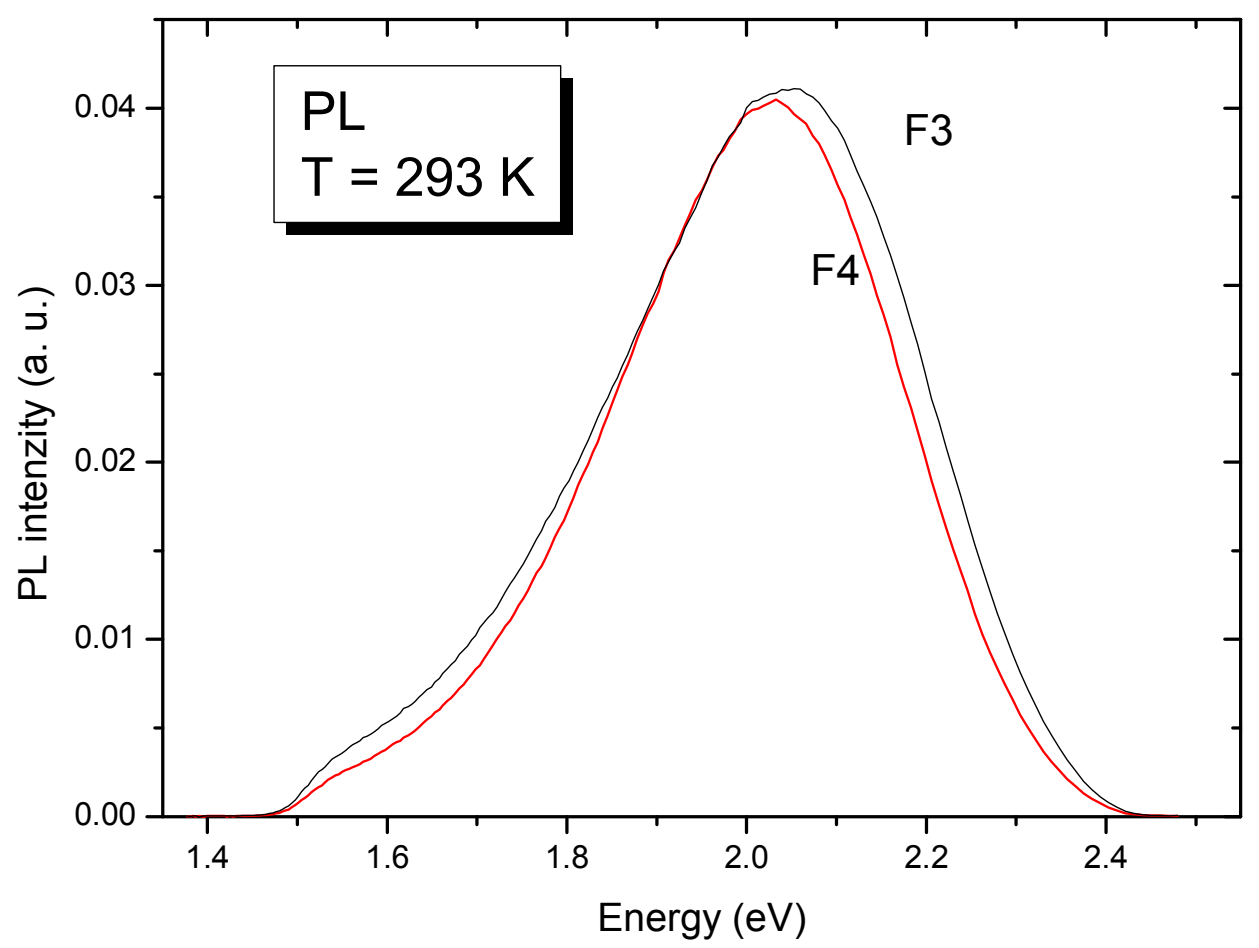

Fig. 7 